\title{
Risk Factors for Disagreement between Self and Proxy Reports on Physical Activity of Children and Young Adolescents
}

\author{
Authors' Contribution: \\ A - Study Design \\ B - Data Collection \\ C - Statistical Analysis \\ D - Data Interpretation \\ E - Manuscript Preparation \\ $F$ - Literature Search \\ G - Funds Collection \\ Alaksander Gałaś (A, C, D, E, F, G), Marzena Florek (A, B, F) \\ Department of Epidemiology, Jagiellonian University Medical College, \\ Krakow, Poland
}

Key words: self report, proxy report, physical activity, children, adolescents

\begin{tabular}{c} 
Background: \\
Material/Methods: \\
Results: \\
$\begin{array}{l}\text { Self and proxy-reports sometimes are the main source of information on physical } \\
\text { activity among schoolchildren. To pool the together, the knowledge on comparability } \\
\text { is required. The main aim of the study was to assess the comparability of data gath- } \\
\text { ered from schoolchildren and their mothers concerning physical activity of youths and } \\
\text { to identify factors associated with disagreement. } \\
\text { A cohort of } 91 \text { children (66\% girls), aged 7-15 years, and their mothers were studied } \\
\text { using a questionnaire in a cross-sectional design. Information gathered included av- } \\
\text { erage leisure time physical activity during the summer and winter weeks over one } \\
\text { year prior to the interview. } \\
\text { The observed level of Lin's concordance correlation coefficient for agreement be- } \\
\text { tween children and their mothers varied from 0.32 for TV/movie viewing to 0.79 for } \\
\text { non-seasonal activity. Sedentary lifestyle (>25.5 hours in sedentary activity/week) } \\
\text { was identified as a factor associated with disagreement in reports on general sea- } \\
\text { sonal activity (OR=5.47, 95\%Cl: 1.78-16.83) and on seasonal team games (OR=5.42, } \\
\text { 95\%Cl: 1.74-16.88). Increase in categories of BMl percentiles was associated with an } \\
\text { increased risk of disagreement (p for trend 0.037, 0.041; respectively). } \\
\text { The comparability of information on the level of children's and young adolescents' } \\
\text { leisure time physical activity depends on the nature of this activity. Sedentary lifestyle } \\
\text { and increased body mass index may be responsible for disagreement in some types } \\
\text { of physical activity. The use of parental proxy reporting as a supplementary source of } \\
\text { information on the level of physical activity of children should be applied, if ever, with } \\
\text { caution. }\end{array}$ \\
\hline
\end{tabular}

Word count: 3.893

Tables: 4

Received: June 2012

Figures: 0

Accepted: December 2012

References: 33

Published: March 2013

Corresponding author:

Aleksander Gałaś, MD, PhD

Department of Epidemiology, Chair of Epidemiology and Preventive Medicine

Jagiellonian University Medical College

Kopernika St 7, 31-034 Krakow, Poland

Phone +48 12 4231003, fax. + 48124228795

E-mail: aleksander.galas@uj.edu.pl 


\section{Introduction}

Although easily accessible and relatively cheap movement instruments have been developed and are used in population studies on physical activity among children, self-report is very often the main source of information. In general, recommendations suggest using objective monitoring (like motion sensors and physiological monitoring) for the measurement of physical activity; however, they mention that 'development and evaluation of these technologies are needed for assessing populations with different activity profiles and socio-demographic characteristics' [1]. A recent review showed more than 20 existing questionnaires with a different level of validity and reliability used all over the world in young people for population surveillance [2]. Self-reports are still the most commonly employed procedures, either interviewer- or self-administered, as these methods are relatively inexpensive, easy to administer and time saving [3,4]. The use of questionnaires, however, to gather data directly from children or adolescents (i.e., the objects of interest) has some limitations. Answers are subjective and may be biased by the level of understanding of certain questions and by the ability to correctly assess the amount of time spent on the activity in question [5].

Some researchers gather data on physical activity (PA) using proxy respondents, such as parents, guardians, or teachers [6,7]. Proxy respondents are easily available in some circumstances. Sometimes investigators decide to collect information from proxy respondents in a case, when the person of interest is unwilling to be interviewed or is too old or too young, thus in studies on children proxies are used relatively often. Young people, because of their agedependent developmental abilities, may be unable to assess the course of time, and thus may provide biased information on their behaviours [8]. Proxy respondents, however, may not have knowledge of the time children spend on different activities, especially, if games or playing have been taken in their absence. Authors sometimes decide to analyse data gathered from children (as one part of a study sample) and from proxy respondents (as a second part of a sample) together [9]. This leads to a question what, beyond the reliability, is the comparability of information obtained by self- and proxy-reports. Moreover, data on the comparability of different sources of recall information (gathered by a questionnaire) on children's PA are scarce and the factors responsible for disagreement have yet to be identified [10].

The main aim of the current study was to assess comparability of data concerning physical activity of schoolchildren collected by a questionnaire administered to youths (self-reporting group) and their mothers (proxy group) as well as to identify factors associated with disagreement.

\section{Material and Methods}

The cross-sectional study was carried out in Krakow, Poland. The study sample covered primary school children. Study participants were recruited among consecutive patients who contacted their General Practitioner (GP, i.e. primary care physician) during the three month study period. Inclusion criteria were age 7-15 years (i.e., primary school age), no dietary restrictions and no dietary related diseases, and the presence of the child's mother during the visit. All those who were given dietary advice by a physician, nutritionist, nurse, etc. due to an underlying health condition or those who were encouraged (by any professional) to control their weight or to increase the level of PA were excluded from the study. Exclusion criteria were verified by questions administered to mother of a child and additionally by information obtained from the child's GP. Informed consent was obtained from the mother of a child. The protocol of the study was approved by the local Bioethical Committee of Jagiellonian University.

Questionnaire. Data on PA were gathered by a questionnaire administered to children and their mothers. Data collection was completed during a face-to-face interview by trained interviewers in a separate waiting room before the meeting with a GP. There was a random sequence in which the questionnaire was administered to respondents (i.e., mother-child or child-mother). Neither the mother nor the child was present when the interview was performed with the other person. GPs were not involved in the process of data collection. Variables included in the questionnaire dealt with an average leisure time PA during summer and winter weeks over one year prior to the interview. The type of and the time devoted to a given PA was measured by the following questions: (1) 'Which of the following physical activity did you do last year, please exclude games 
played during lessons of physical education?'; (2) 'On average, how many days weekly did you do this physical activity?'; and (3) 'On average, how many hours a day did you spend doing this type of physical activity in these days?'. Data concerning sedentary lifestyle were collected using the following questions: (1) 'Did you spend time (outside the school) doing any of the following activities: TV/movie watching, playing PC games, etc.?'; (2) if yes, 'On average, how many days weekly did you do these activities?'; and (3) 'On average, how many hours a day did you spend on these activities in these days?'. All questions were asked separately for summer and wintertime and finally the level of activity was expressed as an average number of hours per week. The type of physical activity named in the questionnaire included biking, swimming, football, roller skating or skateboarding, volleyball, basketball, ballet or dancing, judo or karate, skiing, skating, swimming. The information on TV and movie watching, playing computer games, and doing homework was also collected. The same questions were asked to children and their mothers. To ensure comprehension, the questionnaire was pilot tested prior to implementation in a group of 14 children, aged 8-12 years.

Sample size. It was assumed that in the group of interest (like the predefined group of children with sedentary lifestyle) the frequency of matched reports (meaning that a child reported the same amount of time spent on a particular activity as reported by his/her mother) would be about $40 \%$. The odds ratio for disagreement was expected at about 2.5, the alpha level was assumed at $5 \%$, the power at $90 \%$. Finally, the required sample size was 70 to 100 pairs (child-guardian). During the study period 105 pairs were asked to participate, 6 of them refused (response rate 94.3\%). Additionally, 8 pairs were excluded from the analysis because the guardian was not the child's mother (2 fathers and 6 grandmothers). Finally, 91 (86.7\% of the primary sample) pairs were analysed.

Statistical analysis. Seasonal and non-seasonal activity was defined according to the nature of the activity and a possibility to perform the particular activity during the whole calendar year. Biking, roller-skating, skateboarding, swimming, football, volleyball, basketball, skiing, and skating were considered seasonal activities. Volleyball and basketball were also put into this category, taking into account that most children play these games more frequently during spring and summer and thus the time spent playing these games varies significantly by season. Seasonal activities were divided into two subgroups: team games (i.e., football, volleyball, basketball) and individual games (i.e., biking, roller-skating, skateboarding, swimming, skiing, skating). Time spent on gymnastics, ballet, dancing, judo and karate was summed together and analysed as non-seasonal activity.

Because of the skewness of the data, differences in the information on the level of children's $\mathrm{PA}$, as gathered from the young people themselves and their mothers, were presented using medians and the inter-quartile range and were tested by Wilcoxon's matched-pairs signed-ranks test. Comparability was evaluated by Lin's concordance correlation coefficient for agreement [11]. Next, data were categorised into three levels of PA: 'no', 'lower', and 'higher' activity. 'Lower activity' was defined as time spent on a particular activity being lower than the median, whereas 'higher activity' was defined as time spent being greater than the median. Disagreement was defined as any difference noted in the categories as reported by the mother and her child (i.e. 'lower' category by mother and 'higher' by a child was considered as 'disagreement'). Finally, to reveal risk factors associated with disagreement the logistic regression model was used. Age (as a continuous variable), the body mass index (BMI in categories of percentiles according age and sex [12]: $\leq 50$ th percentile, $>50$ th to 75 th, $>75$ th to 99 th, $>99$ th), and sedentary lifestyle (defined as exceeding the median, i.e. $>25.5$ hours/week) were hypothesized as potential factors associated with disagreement. Sex of a child, mother's education, having a sibling and one of predictors of child's anthropometry like height of the child's father were used as covariates in multiple logistic regression models.

Testing for statistical significance was based on a $5 \%$ level of significance. All statistical analyses were performed using Stata version 10.0 software. 


\section{Results}

The study group covered 91 children and their mothers $(86.7 \%$ of the primary sample). Basic characteristics of the study group are presented in Table 1. In brief, the sample population included 31 boys and 60 girls, mean age 12 years (range $7-15$ years). Boys were slightly younger than girls (11.5 vs. 12.3 years, $p=0.020$ ) and they were found to have a higher BMI.

In total, the participation of a young person in some type of seasonal activity (i.e., at least one of the following: biking, roller-skating, skateboarding, swimming, football, volleyball, basketball, skiing, and skating) was reported by $98 \%$ of the children themselves and $97 \%$ of their mothers. The amount of time spent on these physical activities by children and their proxy respondents varied (median: 10.5 vs. 9.0 hour/week, $p=0.018$ ). The two groups reported also a different amount of time spent on playing team games (i.e., football, volleyball, and basketball) (median: 10.5 vs. 9.3 hour/week, $p=0.038$ ).

Tab. 1. Basic characteristics of the study sample

\begin{tabular}{|c|c|c|c|}
\hline & \begin{tabular}{|l} 
Boys \\
$n=31(34.1 \%)$
\end{tabular} & $\begin{array}{l}\text { Girls } \\
n=60(65.9 \%)\end{array}$ & \\
\hline \multicolumn{4}{|l|}{ Child's age [years] } \\
\hline mean (SD) & $11.5(1.8)$ & $12.3(1.8)$ & \\
\hline $\operatorname{median}\left(Q_{1}-Q_{3}\right)$ & $12(10-13)$ & $12(11-14)$ & $\mathrm{p}^{\mathrm{t}}=0.020$ \\
\hline \multicolumn{4}{|l|}{ Siblings [n, (\%)] } \\
\hline 0 & $6(19.4 \%)$ & $7(11.7 \%)$ & \\
\hline $1+$ & $25(80.7 \%)$ & $53(88.3 \%)$ & $\mathrm{pF}=0.245$ \\
\hline \multicolumn{4}{|l|}{ Child's BMI percentile [n, (\%)] } \\
\hline$\leq 50^{\text {th }}$ & $6(19.4 \%)$ & $27(45.0 \%)$ & \\
\hline$>50^{\text {th }}-75^{\text {th }}$ & $1(3.2 \%)$ & $11(18.3 \%)$ & \\
\hline$>75^{\text {th-99th }}$ & $10(32.3 \%)$ & $17(28.3 \%)$ & \\
\hline$>99^{\text {th }}$ & $14(45.2 \%)$ & $5(8.3 \%)$ & $p F<0.001$ \\
\hline \multicolumn{4}{|l|}{ Mother's education [n, (\%)] } \\
\hline Primary or vocational school & $13(41.9)$ & $28(46.7)$ & \\
\hline Secondary school & $13(41.9)$ & $23(38.3)$ & \\
\hline University & $5(16.1)$ & $9(15.0)$ & $p^{F}=0.955$ \\
\hline
\end{tabular}

Percentages do not sum to $100 \%$ because of rounding; $t-t$ test with equal variances; $F$-Fisher's exact test

When questioned about sedentary lifestyle, children, compared to their mothers, reported more time on television/movie viewing (median: 14.0 vs. 10.5 hour/week, $p=0.0004$ ) and reading books (median: 1.5 vs. 0.5 hour/week, $p=0.012$ ). Time spent on doing homework and on using a computer did not vary significantly between the groups (Table 2). This may reflect higher disparities between mother's knowledge and behaviour of a child in activities that are restricted and might be done by a child during absence of his/her caregiver, like using TV or playing computer games. 
Tab. 2. Weekly time spent on different types of physical activity and sedentary lifestyle reported by children and their proxy respondents

\begin{tabular}{|l|l|l|}
\hline & $\begin{array}{l}\text { Children } \\
{[\text { hour/week }]}\end{array}$ & $\begin{array}{l}\text { Mothers } \\
\text { [hour/week }]\end{array}$ \\
\hline $\begin{array}{l}\text { General seasonal activity } \\
\text { median }\left(Q_{1}-Q_{3}\right)\end{array}$ & $10.5(6.8-18.0)$ & $9.0(4.5-15.5)$ \\
\hline $\begin{array}{l}\text { Seasonal activity -team games } \\
\text { median }\left(Q_{1}-Q_{3}\right)\end{array}$ & $0.9(0.0-3.0)$ & $0.5(0.0-2.0)$ \\
\hline $\begin{array}{l}\text { Seasonal activity -individual games } \\
\text { median }\left(Q_{1}-Q_{3}\right)\end{array}$ & $8.5(6.0-15.0)$ & $7.8(4.0-12.0)$ \\
\hline $\begin{array}{l}\text { Non-seasonal activity } \\
\text { median }\left(Q_{1}-Q_{3}\right)\end{array}$ & $0(0.0-0.8)$ & $0(0.0-0.5)$ \\
\hline $\begin{array}{l}\text { Watching television or movies } \\
\text { median }\left(Q_{1}-Q_{3}\right)\end{array}$ & $14.0(10.5-18.8)$ & $10.5(7.0-14.0)$ \\
\hline $\begin{array}{l}\text { Time spent on } P C \\
\text { median }\left(Q_{1}-Q_{3}\right)\end{array}$ & $0(0.0-1.5)$ & $0(0.0-2.0)$ \\
\hline $\begin{array}{l}\text { Book reading } \\
\text { median }\left(Q_{1}-Q_{3}\right)\end{array}$ & $1.5(0.0-6.0)$ & $0.5(0.0-3.5)$ \\
\hline $\begin{array}{l}\text { Doing homework } \\
\text { median }\left(Q_{1}-Q_{3}\right)\end{array}$ & $9.0(5.0-14.0)$ & $10.0(6.0-14.0)$ \\
\hline
\end{tabular}

The gender subgroup analysis (data not presented) revealed that, in the relation to their proxy respondents, girls more typically reported a longer period of time spent on individual games.

The second aim of the current study was to assess the comparability of data concerning leisure time PA and to identify risk factors associated with disagreement. In general, a moderate level of agreement was observed. However, this agreement was different across different forms of activity. The highest concordance correlation coefficient was observed for non-seasonal activity $(\rho=0.79)$ and the lowest one for general seasonal activity $(\rho=0.48)$. Within types of sedentary lifestyle, the highest concordance correlation was observed for the time spent using a computer $(\rho=0.61)$ and the lowest one for television/movies watching $(\rho=0.32)$ (Table 3).

Tab. 3. Lin's concordance correlation coefficient for agreement on a continuous measure of reported time on physical activity and sedentary lifestyle between children and proxy mother's reports

\begin{tabular}{|l|c|c|c|}
\hline \multirow{2}{*}{} & \multicolumn{3}{|l|}{$\begin{array}{l}\text { Lin's concordance correlation coefficient between children and proxy } \\
\text { mother's reports }\end{array}$} \\
\cline { 2 - 4 } & $\rho$ & $p$ & $95 \% \mathrm{Cl}$ \\
\hline General seasonal activity & 0.48 & $\mathrm{p}<0.001$ & $0.32-0.63$ \\
\hline Seasonal activity -team games & 0.52 & $\mathrm{p}<0.001$ & $0.38-0.65$ \\
\hline Seasonal activity -individual games & 0.49 & $\mathrm{p}<0.001$ & $0.33-0.64$ \\
\hline Non-seasonal activity & 0.79 & $\mathrm{p}<0.001$ & $0.72-0.87$ \\
\hline Watching television or movies & 0.32 & $p<0.001$ & $0.15-0.49$ \\
\hline Time spent on PC & 0.61 & $p<0.001$ & $0.49-0.73$ \\
\hline Book reading & 0.51 & $p<0.001$ & $0.35-0.66$ \\
\hline Doing homework & 0.43 & $p<0.001$ & $0.26-0.60$ \\
\hline
\end{tabular}


The next step of the analysis was to reveal factors associated with disagreement. Sedentary lifestyle ( $>25.5$ hours devoted to sedentary activities/week) was identified as a risk factor for disagreement between data reported by a mother and her child in relation to general seasonal activity $(O R=5.47)$ and in seasonal team games $(O R=5.42)$. Age was also considered; however, no single result was found to be statistically significant. Analysis of the potential role of obesity measured by child's BMI revealed that an increase in categories of BMI percentiles was associated with disagreement for general seasonal PA ( $p$ for trend $=0.037$ ) and for seasonal team games $(p$ for trend $=0.041)($ Table 4$)$.

Tab. 4. Variables considered as potential factors associated with disagreement in the reporting of a child's activity pattern between the proxy respondent (mother) and the child. Multiple logistic regression model $\left({ }^{*}\right)$, odds ratios (ORs)

\begin{tabular}{|c|c|c|c|c|}
\hline \multirow[b]{2}{*}{ Variable of interest } & \multicolumn{4}{|c|}{ ORs (with $95 \% \mathrm{Cls}$ ) for disagreement in: } \\
\hline & $\begin{array}{l}\text { General seasonal } \\
\text { activity }\end{array}$ & $\begin{array}{l}\text { Seasonal activity - } \\
\text { team games }\end{array}$ & $\begin{array}{l}\text { Seasonal activity - } \\
\text { individual games }\end{array}$ & Non-seasonal activity \\
\hline $\begin{array}{l}\text { Age } \\
\text { (increase in } 1 \text { year) }\end{array}$ & $1.33(0.90-1.95)$ & $0.86(0.60-1.22)$ & 1.34 (0.95-1.87) & $0.71(0.45-1.12)$ \\
\hline $\begin{array}{l}\text { BMI }\left(\mathrm{kg} / \mathrm{m}^{2}\right) \text { percentiles } \\
\leq 50^{\text {th }} \text { percentile } \\
>50^{\text {th }} \text { to } 75^{\text {th }} \\
>75^{\text {th }} \text { to } 99^{\text {th }} \\
>99^{\text {th }} \\
p \text { for trend }\end{array}$ & $\begin{array}{l}1 \\
2.96(0.53-16.55) \\
1.66(0.40-6.85) \\
12.96(1.85-16.55) \\
p_{t}=0.037\end{array}$ & $\begin{array}{l}1 \\
2.02(0.34-11.97) \\
3.81(0.94-15.45) \\
4.77(0.79-28.71) \\
p_{t}=0.041\end{array}$ & $\begin{array}{l}1 \\
2.19(0.50-9.60) \\
0.78(0.23-2.65) \\
2.00(0.39-10.19) \\
p_{t}=0.936\end{array}$ & $\begin{array}{l}1 \\
0.64(0.06-7.34) \\
0.59(0.10-3.41) \\
0.67(0.08-5.81) \\
p_{t}=0,474\end{array}$ \\
\hline $\begin{array}{l}\text { Sedentary lifestyle ** } \\
(>25.5 \text { hour/week })^{\dagger}\end{array}$ & $5.47(1.78-16.83)$ & $5.42(1.74-16.88)$ & $2.20(0.82-5.92)$ & $1.03(0.25-4.19)$ \\
\hline
\end{tabular}

${ }^{*}$ - adjusted for mother's education, having a sibling, height of the child's father and other covariates presented in the table; ${ }^{* *}$ - adjusted for all variables as in * and additionally for child's sex; $\dagger$ - as reported by children

\section{Discussion}

The supplementary use of proxy respondents in epidemiologic investigations meant to assess child's physical activity (PA) has seldom been studied. The presented results provide information on the level of agreement between proxy (i.e., mothers) and school-aged child respondents regarding leisure time PA and elements of sedentary lifestyle. The observed levels of agreement in the study varied between $0.32-0.79$ and were the highest for non-seasonal activity. The levels of agreement were similar to other studies investigating comparability of the data reported by children and their proxies. Among the myriad of risk factors measured in children participating in survey interviews, the most commonly evaluated were tobacco, alcohol, and illicit drug use. Observed levels of agreement in those studies [13, 14, 15], expressed by correlation coefficients, were similar to values found in the current study.

Whiteman and Green [16], who investigated agreement between parent-proxy and child respondents, found a very high correlation level for unchanging physical characteristics (e.g., eye $(\rho=0.88)$ or hair colour $(\rho=0.76))$ and a history of residing on a farm $(\rho=0.84)$ as well as moderate to lower agreement levels on skin changes or being sunburnt. The paper on levels of agreement between 6th- to 7th-grade students and their parents in self-reported sun behaviours was also published by Dusza et al. [17]. They found a weighted kappa ranging from 0.23 for wearing a shirt on sunny days to 0.73 for skin colour. Jozefiak [18] had compared child and parent-by proxy ratings of child's quality of life and he observed low to moderate $(\rho=0.32)$ correlations in the KINDL-R questionnaire for measuring health-related quality of life among children and adolescents and also in the Inventory of Life Quality. Reports on other activities were even poorer. Inyang [19] had investigated how well adolescents (secondary schools students) recall the use of mobile telephones and he noticed a modest rank correlation for the number of voice calls $(\rho=0.3)$ and poor agreement in the duration of calls $(\rho=0.1)$. 
There are some possible explanations for a relatively low level of agreement (measured by Lin's concordance correlation coefficient) observed in our study. The first is the age characteristic of the study group. Due to young age schoolchildren may have a lower ability to correctly report information regarding the time spent on PA. Although data gathered from children through recall may be questionable, school-age children may have knowledge of self-behaviours of which their parents or other proxies are unaware [20] and thus they are a valuable source of information. Observed correlation coefficients might also be lower because of the lower level of understanding presented by children. However, children in this study had a high level of agreement for other easy verifiable data, like how many siblings the child had (weighted kappa $=0.99$ for data reported by the proxy respondent and the child), or the child's age (the concordance correlation coefficient=1.00).

The second reason for disagreement may be the measurement technique. To avoid bias in our study, the same questions were used for proxy and child respondents, the questionnaire was tested for comprehension in children, and, additionally, interviews were performed interchangeably between the proxy- and self-respondent in the absence of the other person.

Thirdly, reporting time might have influenced agreement. The assessment of PA over the past year seems to be less accurate compared to, for example, the last 7 days, the time period for PA research suggested by some authors [21]. In the presented study habitual average physical activity over a period of a calendar season or of one year (for more "stable" activities) was used because, for most, especially retrospective, investigations, the assessment of a shorter period is not sufficient enough to evaluate PA patterns. It is still open discussion, however, on the reliability of this type PA questionnaires. However, even though the latter analysis has showed that there is no questionnaire available with both acceptable reliability and validity [22], PA questionnaires are still used very often [2].

Questionnaires administered to children and their mothers reflected the same reference period, thus, a possible error related to the time in question, if present, should be similar in both groups. We need to keep in mind, however, that there is a relatively high probability that the potential of correctly remembering the amount of time spent on different forms of PA is lower among children (i.e., self-respondents) compared to their mothers (i.e., proxy respondents). Also, sex distribution among children might play a role in assessing levels of agreement $[23,24,25]$. Finally, while asked, respondents, either children or their mothers, might try to recall "politically correct" responses reporting a higher amount of time spent on the specific type of questioned physical activity. This is a recurrent problem in self-reported data; however, we believe that, if present, it skews data in a similar way among children and their guardians, and thus mildly influences the level of agreement.

Others factors, such as the nature of exposure, may also play a role. As it was observed after a detailed data analysis in the study, the correlation coefficient was definitely higher for activities performed in a regular, organised manner (e.g., judo, gymnastics, organized swimming pool sessions in wintertime), compared to other activities (e.g., TV/movie watching, volleyball, or even doing homework). Overall the coefficients of correlation between the guardian and the child recalls were relatively weak. This was observed mainly because of the period of the questioned time, which was relatively long. Parents or guardians usually do not have complete knowledge of some forms of activities, most often performed in a child's leisure time in the absence of a parent, even test-retest reliability for questions regarding these activities was relatively high for questionnaires, as it was observed in different investigations [26, 27]. Very often guardians are not close enough and this may also explain their relatively poor knowledge concerning some child's exposures. A variety of studies investigating different childhood experiences found that proxy respondents had little knowledge on tobacco smoking [28], solvents [29], sexual behaviours [30], bicycle helmets use [31], and also on physical activity [32]. In this paper we assess the level of comparability between two sources of data (mother and her child), and, because of subjective individual assessment reported by the mother and the child, the level of reliability of the instrument (questionnaire) mildly influences the level of differences in reports, which rely on knowledge and individual perception.

The second part of this study focused on possible risk factors associated with disagreement on physical activity in child's self- and mother/proxy-reporting. Potential risk factors included age, body 
mass index and sedentary lifestyle. Sedentary lifestyle was revealed as a risk factor for disagreement in general seasonal activity and seasonal activities - team games. Age was not confirmed as a risk factor, as it was observed in some other studies, even if relatively young schoolchildren were recruited in the study. However, in the study group the majority of children were at the age of 9-12, and small variability might hinder showing the role of this characteristic.

In our study an increased risk of disagreement was observed with an increase in the level of the child's BMI (Table 4). BMI has been observed to be a risk factor for under-reporting in dietary studies [33]. Overweight children have usually lower activity levels as recommended and this may influence reporting. Similarly to dietary studies, in the presented study, the child's BMI was also recognized as a possible risk factor for disagreement in physical activity reports.

Our study was able to supplement existing knowledge regarding the factors responsible for inconsistency in reporting children's PA. The advantages of this study included also considering several confounding variables in logistic regression analyses while simultaneously looking for factors associated with disagreement.

Among limitations it should be noticed that the level of agreement and the risk factors for disagreement were investigated considering the frequency and duration of physical activity but not intensity. We expect that reports regarding the level of intensity and duration of activities with different intensity levels vary much more between children and their guardians; however, factors responsible for disagreement were not investigated and require further studies.

Although the current study did not investigate validity of recall information on child's and adolescent's PA, the investigation provides some suggestions regarding the knowledge of factors associated with disagreement which can allow future interpretation of such differences. Moreover, our results may help to decide if it is reasonable to analyse together data coming from different sources like self and proxy reports.

Several factors like sex, age, sedentary lifestyle, BMI and some other personal characteristics may influence data quality with regard to physical activity. Overall, the use of parental proxy reporting as a supplementary source of information regarding the level of physical activity of children should be applied, if ever, with caution.

\section{Conclusions}

The study showed that the comparability of self and proxy reports regarding child's leisure time physical activity depends on the nature of this activity and disagreement is more likely for seasonal activities. Moreover, sedentary life-style and body mass index are both associated with disagreement. Thus, the use of parental proxy reporting as supplementary source of information regarding the level of physical activity of children should be applied, if ever, with caution.

\section{Acknowledgments}

Thanks to Dr Marek Kopacz MD, PhD for language revision and to Anna Wisniewska for the contribution to the data collection.

\section{References}

1. Physical Activity Guidelines Advisory Committee Report, 2008. Washington, DC: U.S. Department of Health and Human Services [bhttp://health.gov/paguidelines] [accessed on Feb 16, 2012]

2. Biddle SJ, Gorely T, Pearson N, Bull FC. An assessment of self-reported physical activity instruments in young people for population surveillance: Project ALPHA. Int J Behav Nutr Phys Act 2011;8:1.

3. Gordon-Larsen P, McMurray RG, Popkin BM. Determinants of adolescent physical activity and inactivity patterns. Pediatrics 2000;105:e83.

4. Livingstone MB, Robson PJ, Wallace JM, McKinley MC. How active are we? Levels of routine physical activity in children and adults. Proc Nutr Soc 2003;62:681-701.

5. Durante R, Ainsworth BE. The recall of physical activity: using a cognitive model of the questionanswering process. Med Sci Sport Exerc 1996;28:1282-1291.

6. Taylor RW, Murdoch L, Carter P, Gerrard DF, Williams SM, Taylor BJ. Longitudinal study of physical activity and inactivity in preschoolers: The FLAME study. Med Sci Sport Exerc 2009;41:96-102.

7. Sirard JR, Pate RR. Physical activity assessment in children and adolescents. Sports Med 2001;31:439454. 
8. Anderson VA, Lajoie G. Development of memory and learning skills in school-aged children: a neuropsychological perspective. Appl Neuropsychol 1996;3:128-139.

9. Robitail S, Simeoni M, Erhart M, Ravens-Sieberer U, Bruil J, Auquier P. Validation of the European proxy KIDSCREEN-52 pilot test health-related quality of life questionnaire: First results. Journal of Adolescent Health 2006;39:596.e1-596.e10.

10. Chaumeton N, Duncan SC, Duncan TE, Strycker LA. A measurement model of youth physical activity using pedometer and self, parent, and peer reports. Int J Behav Med 2011;18:209-15.

11. Rosner $\mathrm{B}$, Hennekens $\mathrm{CH}$. Analytic methods in matched pair epidemiological studies. Int $J$ Epidemiol 1978;7:367-372.

12. World Health Organization. WHO growth reference 2007 data for $5-19$ years [http://www.who.int/growthref/en] [accessed on-line on Mar 7, 2012]

13. Parra GR, O'Neill SE, Sher KJ. Reliability of self-reported age of substance involvement onset. Psychol Addict Behav 2003;17:211-218.

14. Lintonen T, Ahlstrom S, Metso L. The reliability of self-reported drinking in adolescence. Alcohol 2004;39:362-368.

15. 15. Johnson TP, Mott JA. The reliability of self-reported age of onset of tobacco, alcohol and illicit drug use. Addiction 2001;96:1187-1198.

16. Whiteman D, Green A. Wherein lies the truth? Assessment of agreement between parent proxy and child respondents. Int J Epidemiol 1997;26:855-859.

17. Dusza SW, Oliveria SA, Geller AC, Marghoob AA, Halpern AC. Student-parent agreement in selfreported sun behaviors. J Am Acad Dermatol 2005;52:896-900.

18. Jozefiak T, Larsson B, Wichstrom L, Mattejat F, Ravens-Sieberer U. Quality of life as reported by school children and their parents: A cross-sectional survey. Health Qual Life Outcomes 2008;19:6-34.

19. Inyang I, Benke G, Morrissey J, McKenzie R, Abramson M. How well do adolescents recall use of mobile telephones? Results of a validation study. BMC Med Res Methodol 2009;12:9-36.

20. Sawyer MG, Baghurst P, Clark J. Differences between reports from children, parents and teachers: Implications for epidemiological studies. Aust N Z J Psychiatry 1992;26:652-660.

21. Levin S, Jacobs DR, Ainsworth BE, Richardson MR, Leon AS. Intra-individual variation and estimates of usual physical activity. Ann Epidemiol 1999;9:481-488.

22. Chinapaw MJ, Mokkink LB, van Poppel MN, van Mechelen W, Terwee CB. Physical activity questionnaires for youth: a systematic review of measurement properties. Sports Med 2010;40:539-563.

23. Marcotte L, Hennessy E, Dwyer J, et al. Validity and reliability of a calcium checklist in early elementaryschool children. Public Health Nutr 2008;11:57-64.

24. Dollman J, Ridley K, Magarey A, Martin M, Hemphill E. Dietary intake, physical activity and TV viewing as mediators of the association of socioeconomic status with body composition: A cross-sectional analysis of Australian youth. Int J Obes 2007;31:45-52.

25. Voyer D, Postma A, Brake B, Imperato-McGinley J. Gender differences in object location memory: A meta-analysis. Psychon Bull Rev 2007;14:23-38.

26. Evenson KR, Birnbaum AS, Bedimo-Rung AL, et al. Girls' perception of physical environmental factors and transportation: reliability and association with physical activity and active transport to school. Int $J$ Behav Nutr Phys Act 2006;3:28.

27. Huang YJ, Wong SH, Salmon J, Hui SS. Reliability and validity of psychosocial and environmental correlates measures of physical activity and screen-based behaviors among Chinese children in Hong Kong. Int J Behav Nutr Phys Act 2011;8:16

28. Bush PJ, lannotti RJ. Alcohol, cigarette, and marijuana use among fourth-grade urban schoolchildren in 1988/89 and 1990/91. Am J Public Health 1993;83:111-114.

29. Tapia-Conyer R, Cravioto P, De La Rosa B, Velez C. Risk factors for inhalant abuse in juvenile offenders: The case of Mexico. Addiction 1995;90:43-49.

30. Shew ML, Fortenberry JD, Miles P, Amortegui AJ. Interval between menarche and first sexual intercourse, related to risk of human papillomavirus infection. J Pediatr 1994;125:661-666.

31. Thomas S, Acton C, Nixon J, Battistutta D, Pitt WR, Clark R. Effectiveness of bicycle helmets in preventing head injury in children: Case-control study. BMJ 1994;308:173-176.

32. Wolf AM, Gortmaker SL, Cheung L, Gray HM, Herzog DB, Colditz GA. Activity, inactivity, and obesity: Racial, ethnic, and age differences among schoolgirls. Am J Public Health 1993;83:1625-1627.

33. Singh R, Martin BR, Hickey $\mathrm{Y}$, et al. Comparison of self-reported, measured, metabolizable energy intake with total energy expenditure in overweight teens. Am J Clin Nutr 2009;89:1744-1750. 


\section{Appendix}

\section{THE STRUCTURE OF QUESTIONS COLLECTING DATA ON PHYSICAL ACTIVITY}

\begin{tabular}{|c|c|c|c|}
\hline \multicolumn{4}{|c|}{$\begin{array}{l}\text { Which of the following physical activities did you do last year in summertime, please exclude games played during lessons of } \\
\text { physical education? }\end{array}$} \\
\hline & type of physical activity & $\begin{array}{l}\text { On average, how many days weekly did } \\
\text { you do this physical activity?' }\end{array}$ & $\begin{array}{l}\text { On average, how many hours a day did you } \\
\text { spend doing this type of physical activity in } \\
\text { these days? }\end{array}$ \\
\hline 1 & biking & & \\
\hline 2 & swimming & & \\
\hline 3 & football & & \\
\hline 4 & $\begin{array}{l}\text { roller skating or skate- } \\
\text { boarding }\end{array}$ & & \\
\hline 5 & volleyball & & \\
\hline 6 & basketball & & \\
\hline 7 & ballet or dancing & & \\
\hline 8 & judo or karate & & \\
\hline 9 & gymnastics & & \\
\hline 10 & others & & \\
\hline \multicolumn{4}{|c|}{$\begin{array}{l}\text { Which of the following physical activities did you do last year in wintertime, please exclude games played during lessons of } \\
\text { physical education? }\end{array}$} \\
\hline & type of physical activity & $\begin{array}{l}\text { On average, how many days weekly did } \\
\text { you do this physical activity?' }\end{array}$ & $\begin{array}{l}\text { On average, how many hours a day did you } \\
\text { spend doing this type of physical activity in } \\
\text { these days? }\end{array}$ \\
\hline 1 & swimming & & \\
\hline 2 & $\begin{array}{l}\text { roller skating or skate- } \\
\text { boarding }\end{array}$ & & \\
\hline 3 & volleyball & & \\
\hline 4 & basketball & & \\
\hline 5 & ballet or dancing & & \\
\hline 6 & judo or karate & & \\
\hline 7 & skiing & & \\
\hline 8 & skating & & \\
\hline 9 & others & & \\
\hline \multicolumn{4}{|c|}{ Did you spend time (outside the school) doing any of the following activities in summertime: } \\
\hline & type of activity & $\begin{array}{l}\text { On average, how many days weekly did } \\
\text { you do this activity? }\end{array}$ & $\begin{array}{l}\text { On average, how many hours a day did you } \\
\text { spend on this activity in these days }\end{array}$ \\
\hline 1 & TV viewing & & \\
\hline 2 & movie viewing & & \\
\hline 3 & playing computer games & & \\
\hline 4 & reading a book & & \\
\hline 5 & doing homework & & \\
\hline \multicolumn{4}{|c|}{ Did you spend time (outside the school) doing any of the following activities in wintertime: } \\
\hline & type of activity & $\begin{array}{l}\text { On average, how many days weekly did } \\
\text { you do this activity? }\end{array}$ & $\begin{array}{l}\text { On average, how many hours a day did you } \\
\text { spend on this activity in these days }\end{array}$ \\
\hline 1 & TV viewing & & \\
\hline 2 & movie viewing & & \\
\hline 3 & playing computer games & & \\
\hline 4 & reading a book & & \\
\hline 5 & doing homework & & \\
\hline
\end{tabular}

